Relations industrielles

Industrial Relations

\title{
Labour Terms. Montreal 1, 132 St. James St.: CCH Canadian Limited, 1958. 94pp.
}

\section{Gérard Dion}

Volume 13, numéro 3, juillet 1958

URI : https://id.erudit.org/iderudit/1022434ar

DOI : https://doi.org/10.7202/1022434ar

Aller au sommaire du numéro

Éditeur(s)

Département des relations industrielles de l'Université Laval

ISSN

0034-379X (imprimé)

1703-8138 (numérique)

Découvrir la revue

Citer ce compte rendu

Dion, G. (1958). Compte rendu de [Labour Terms. Montreal 1, 132 St. James St.: CCH Canadian Limited, 1958. 94pp.] Relations industrielles / Industrial

Relations, 13(3), 353-353. https://doi.org/10.7202/1022434ar

Tous droits réservés (C Département des relations industrielles de l’Université Laval, 1958
Ce document est protégé par la loi sur le droit d'auteur. L’utilisation des services d'Érudit (y compris la reproduction) est assujettie à sa politique d'utilisation que vous pouvez consulter en ligne.

https://apropos.erudit.org/fr/usagers/politique-dutilisation/ 
L'apport de Mayo et de ses successeurs n'en est nullement amoindri. Mais il nous apparaît mieux comme un secteur particukier d'une probiématique plus générale dont $M$. Touraine nous révèle une nouvelle dimension.

\section{Fernand Dumont}

Labour Terms. Montreal 1, 132 St. James St.: $\mathbf{C C H}$ Canadian Limited, 1958. $94 \mathrm{pp}$.

Il y a quelques années, CCH Canadian Limited diffusait au Canada une brochure américaine très utile sous le titre «Dictionary of Labor Law Terms ». On a repris cet ouvrage pour lui donner une ampleur plus considérable, et on en a fait une édition typiquement canadienne.

On trouve dans cet ouvrage une brève définition des termes et des phrases utilisés dans les conventions collectives, les décisions arbitrales et la législation du travail.

Ce petit travail sans prétention scientifique est d'une grande utilité pratique, immédiate pour tous ceux qui ont à s'occuper des relations du travail. Bien plus, il contribue à préciser le langage et à éviter les discussions oiseuses à base d'équivoques sur la signification des mots.

Souhaitons qu'un ouvrage du même genre soit publié en français.

G.D.

Fernand Dumont: professeur de Sociologie, Faculté des sciences sociales de Laval;

G.D. et Roger Chartier: professeurs de Relations industrielles, Faculté des sciences sociales de Laval.

\section{A ne pas manquer !}

Le Rapport du Douxième Congrès des Relations industrielles de Laval, traitant des

Changements ÉCONOMiques et TRANSFormations SYNDicales

Un volume de près de 200 pages $-\$ 3.00$

En vente d̀ :

LES PRESSES UNIVERSITAIRES LAVAL

28, rue Ste-Famille, Québec. 